\title{
REVIEW
}

\section{Research progress and developing prospect of fly ash}

\author{
Yuqing Peng $^{1^{*}} \quad$ Runjin Yang ${ }^{1}$
}

\begin{abstract}
The perspectives of the quality and composition of fly ash. The comprehensive usage of fly ash hazard-free treatment and recycling of fly ash. The application of fly ash in construction, agriculture, industrial production and environmental protection. The status quo and prospects of China's comprehensive usage of fly ash.
\end{abstract}

Keywords: fly ash, solid waste, comprehensive usage sour Environ Inf Eng, 2019, 1(1): 18-22.

Copyright: (c) 2019 Yuqing Peng, et al. This is an open access article distributed under the terms of the Creative Commons Attribution License, which permits unrestricted use, distribution, and reproduction in any medium, provided the original author and source are credited. 


\title{
综述
}

\section{粉煤灰综合利用研究进展}

\author{
彭雨晴 $1^{*} \quad$ 羊润锦 1
}

摘 要: 根据粉煤灰的性质和组成, 基于对粉煤灰无害化、资源化的综合利用为前提, 阐述其在 建筑、农业、工业、环保等方面的应用，简要总结我国对其综合利用的现状和展望。

关键词：粉煤灰，固体废物，综合利用

\section{1 引言}

粉煤灰也称飞灰, 主要是经燃煤电厂等企业排 出所得的副产物。随着火力发电的广泛应用, 粉煤 灰的产量也逐年递增, 目前我国堆存量已有近 20 亿 吨 ${ }^{[1]}$ 。大量的粉煤灰长期堆放既占用大量土地, 还 是会对土壤、空气、水造成严重的污染和破坏, 目 前我国粉煤灰的排放已经对环境造成空前的压力, 已经威胁到了动植物的生存。

\section{2 粉煤灰组成及性质}

\section{1 粉煤灰化学及矿物组成}

要对粉煤灰进行综合利用就要了解粉煤灰的化 学成分, 由此才能对粉煤灰的品质优势进行评价。 粉煤灰的无机成分以粘土矿为主, 其中含有 $\mathrm{SiO}_{2}$ (质 量分数 $40 \%-60 \%) 、 \mathrm{~A}_{2} \mathrm{O}_{3}(17 \%-35 \%) 、 \mathrm{Fe}_{2} \mathrm{O}_{3}(2 \%$ $15 \%) 、 \mathrm{CaO}(1 \%-10 \%)$ 和未燃炭。

粉煤灰的矿物组成非常复杂, 通常来说没有绝 对纯净的煤, 不同的煤中含有成分不同含量不同的 无机成分, 而这种无机物为粉煤灰中的矿物, 大部 分是以晶体形态存在; 还有一些煤是以无定形形式 存在, 无定性形态主要为玻璃相, 是粉煤灰中粘土 矿物失去水分而形成的, 约占粉煤灰总量的 $50 \%$ 80\%，此外未燃尽的碳粒也属于无定形相。

\section{2 物理性质}

粉煤灰形态为粉末状, 颜色有的灰色、灰白色 和灰黑色, 由颜色可大致判断粉煤灰的含碳量的多

\footnotetext{
收稿日期: 2019/07/31; 录用日期: 2019/08/09; 发表日期: 2019/08/12

*通讯作者: 彭雨晴, 成都信息工程大学资源环境学院, 成都 610103, 中 国; Email: 534798998@qq.com

${ }^{1}$ 成都信息工程大学资源环境学院, 成都 610103, 中国

引用: 彭雨晴, 羊润锦. 粉煤灰综合利用研究进展. 资源环境与信息工程, 2019, 1(1): 18-22.

版权: (c) 2019 彭雨晴, 等.
}

少，颜色为灰黑色的粉煤灰说明它的炭粒未完全燃 烧, 含碳量较大, 因此颜色对于粉煤灰是一项很重 要的物理指标。由于煤炭燃烧后产生的粉煤灰是经 过高温形成的, 在形成过程中, 由表面张力作用, 部分呈球形, 表面光滑, 微孔较小。

粉煤灰主要由钢玉石、莫来石等矿物组成, 这 些矿物堆积紧密程度决定粉煤灰的密度 ${ }^{[2]}$ 。粉煤 灰密度范围在 $1.77-2.43 \mathrm{~g} / \mathrm{cm}^{3}$, 平均密度为 $2.1 \mathrm{~g} / \mathrm{cm}^{3}$ 。 孔隙率一般为 $60 \%-75 \%$; 粒度一般为 $45 \mu \mathrm{m}$; 比表面 积为 $2000-4000 \mathrm{~cm}^{2} / \mathrm{g}$ 。

\section{3 化学性质}

粉煤灰具有火山灰活性, 可以很好的作为资源 进行综合利用。其主要的化学成分为 $\mathrm{SiO}_{2} 、 \mathrm{Al}_{2} \mathrm{O}_{3}$, 除此之外还包含一些有害成分如游离氧化钙、三氧 化硫和氯离子, 这些离子会影响水泥的强度和钢筋 的耐久性。

\section{3 粉煤灰的综合利用技术}

我国对于粉煤灰的综合利用起步晚, 最开始主 要是在建筑方面有所利用。随着对粉煤灰结构成分 特点的了解, 粉煤灰逐渐被广泛利用在在建材、筑 路、农业、工业、环保等方面。

\section{1 粉煤灰用作建筑材料}

资料显示在国外粉煤灰超过 $20 \%$ 作为建筑材料 使用, 我国粉煤灰综合利用率约为 $67 \%$, 而其中很 大一部分占比用于制作建筑材料, 这一比例超过了 美国等发达国家 ${ }^{[3,4]}$ 。在建筑材料中粉煤灰常做为配 制不同比例的水泥, 砂浆, 和各种砌块等的原料。

(1) 粉煤灰水泥。通过薛福连 ${ }^{[5]}$ 分析结果 表明, 由于粉煤灰中含有大量的活性 $\mathrm{A}_{2} \mathrm{O}_{3}$ 、 $\mathrm{SiO}_{2}$ 及 $\mathrm{CaO}$ 等, 其成分与粘土成分相近, 所以可以 替代部分粘土来作为生产水泥的原材料。李荣佳 ${ }^{[6]}$ 研究表明通过调和适当比例的硅酸盐水泥和粉煤来 
灰，并且加入适量的石膏制造出来的水泥浆强度与 普通水泥相当。也有研究表明[7] 与普通硅酸盐水泥 相比, 采用化学激发和机械活化的方法, 粉煤灰水 泥在降低干缩性和水化热的同时，还能有很好的抗 油和抗裂性。该水泥早期强度低, 但后期强度增长 快，且耐硫酸盐性能好，并且该水泥制造方式能降 低生产成本, 能广泛应用于一般民用、工业建筑工 程及水利工程、地下工程和海港工程, 有较好的经 济效益。

(2) 粉煤灰混凝土。粉煤灰混凝土是以硅酸盐水 泥为胶结料、砂石子以及掺入一定量粉煤灰加水配 制而成。因为粉煤灰具有火山灰活性, 所以可以用 作混凝土参料 ${ }^{[8]}$ 。实践表明, 粉煤灰能减少水化热、 干缩率有效改善混凝土的性能, 所以用粉煤灰代替 传统水泥, 不仅能提高混凝土性能, 还可以降低成 本。

(3) 粉煤灰制砖。因为粉煤灰的成分与粘土相 似, 因此可以替代粘土, 经过加工焙烧制成多孔砖 或空心砖 ${ }^{[9]}$ ，粉煤灰的加人量可达30\%-80\%。与粘 土烧制的砖相比, 有质量轻、强度高、耐久性好、 抗冻融性强、不易粉化、保温隔热性能优良等特点。 当粉煤灰的掺入量在 $65 \%$ 左右, 制成品的抗折性能 较差。

(4) 粉煤灰陶粒。将粉煤灰中加入少量黏结剂和 固体燃料, 加工成球后, 再高温烧结而制得的一种 轻质骨料颗粒即为粉煤灰陶粒。粉煤灰陶粒主要物 理力学性能有质量轻、强度高、热导率低、化学稳 定性好、保温、阻燃等, 因此优于天然石料, 可用 于混凝土砌块等新型墙体材料。

\section{2 筑路回填}

(1) 筑路。粉煤灰在路基工程中运用中, 具有透 气性大、活性高、干密度低、黏结性小等特点, 因 此常作为优质筑路材料 ${ }^{[10]}$ 。由于掺入粉煤灰后路面 隔热性能好, 防水性和板体性也有提高, 并且也解 决了粉煤灰堆积的问题, 因此粉煤灰被大量运用于 筑路中。通过实验证明, 除了在普通道路路基上的 运用, 粉煤灰还可用作铁路路基填料, 且填筑的路 基相当稳定 ${ }^{[11]}$ 。

(2) 回填。煤矿区经过长期的采煤后易造成塌陷 和形成洼地, 会有许多的安全隐患。利用粉煤灰对 矿区的煤坑、洼地进行回填是粉煤灰综合应用最直 接和有效的方式, 既利用消耗了大量的粉煤灰来降 低了塌陷程度, 还加强了围岩和煤柱起到了防火的 效果, 改善了矿区生态。粉煤灰还可调节粗粒尾砂 的级配, 改善粘土质尾砂的通水通气性能。

\section{3 粉煤灰在农业方面应用}

粉煤灰在农业上的应用实际包括对土壤的改良 提高农作物的产量和作为肥料为农作物提供所需的 营养元素。在农业上的应用具有投资少，消耗量大 等特点, 是一条符合我国国情实现粉煤灰资源化的 有效途径。

(1) 用作土壤改良剂。粉煤灰自身具有松散多 孔, 比表面积大, 粒度细等物理特性, 能保存和传 送水分、营养物质、空气热量，且因其具有良好的 物理化学性能, 可用于改造重黏土、生土、酸性土 和盐碱土。粉煤灰加入土壤中, 在增加土壤中的的 铜、嗍、锌、锰等微量元素和稀土元素含量的同时, 还可以改善土壤的质地和结构, 改变容重、空隙率 和通水透气性能, 使酸性团粒结构改善, 并抑制盐 碱, 从而提高土壤微生物活性 ${ }^{[12]}$, 有利于微生物生 长繁殖并对土壤中有机物进行分解, 提高土壤的有 效养分含量和保温保水能力, 增强作物的防病抗旱 能力。

（2）用作农业肥料。粉煤灰因为是矿物质燃烧的 直接产物, 所以含有大量的易溶性的镁、钙、钾、 磷等农作物必需的营养元素, 还有少量的铜、嗍、 锌、锰等微量元素。可用于代替部分肥料添加剂, 制成优质肥料。此外, 粉煤灰中含有大量 $\mathrm{SiO}_{2}$ 、 $\mathrm{CaO} 、 \mathrm{MgO}$ 及少量 $\mathrm{P}_{2} \mathrm{O}_{5} 、 \mathrm{~S} 、 \mathrm{Fe} 、 \mathrm{Mo} 、 \mathrm{~B} 、 \mathrm{Zn}$ 等有 用成分。因此, 也可制成各种农业化肥如硅肥、粉 煤灰氮磷肥、粉煤灰复混肥和粉煤灰磁化肥。这些 肥料使用后农作物总干重增加, 根系发达茎秆粗壮, 产量也大幅提高, 有很好的经济利用价值。

\section{4 回收工业原料}

(1) 回收煤炭。一般粉煤灰中含碳回收煤炭的 方法量约5\%-16\%。粉煤灰中含炭量太多，对粉煤灰 建材(尤指蒸养制品)的质量和从粉煤灰中提取漂珠 的质量有不良影响, 同时也浪费了资源, 因此需对 其进行回收。回收煤炭常采用浮选法和干静电分选 法。浮选法可以从粉煤灰中分选出得到精碳、中碳 和尾灰三种产品, 精碳的固定碳含量可达到64\%以 上, 中碳中的固定碳含量可达 $51 \%$ 以上, 尾碳的碳 含量则小于 $5 \%$ 或 $3 \%$; 另一种是干灰静电分选煤炭, 利用煤和灰的介电性能不同，进入高压电场后，发 生电性差异而被分选出来, 此方法在回收过程中没 有造成二次污染, 并且成本低。

(2) 回收金属物质。粉煤灰中含有三氧化二铝、 三氧化二铁和大量稀有金属，在一定条件下，这些 金属物质都可回收。采用磁选法可对铁进行回收, 其回收率可达 $40 \%$ 以上。粉煤灰中的 $\mathrm{Fe}_{2} \mathrm{O}_{3}$ 含量一般 在 $4 \%-20 \%$ 之间，最高达 $43 \% ，$ 因此可从含少量铁的 
粉煤灰中提取含铁量 $50 \%$ 以上的铁精矿粉。除此之 外还可用高温熔融法、热酸淋洗法、直接熔解法回 收铝, 采用碱溶法从含有三氧化二铝粉煤灰中提取 氧化铝, 一般要求 $\mathrm{Al}_{2} \mathrm{O}_{3}$ 含量大于 $25 \%$ 时方可回收。

(3) 分选空心微珠。空心微珠的密度一般只有粉 煤灰的 $1 / 3$, 粒径为 $0.3-300 \mu \mathrm{m}$ 。目前, 国内主要用以 空气为介质的干法机械分选工艺和以水为介质的湿 法分选工艺。湿法工艺从分选效果来看要比干法机 械分选要好些, 确定工艺流程前要根据粉煤灰的具 体特性和珠体含量来选择, 一般湿法排灰的工厂采 用此方法。空心微珠具有抗压强度、高的耐火度、 高的电阻率、高的耐腐蚀率、低的热传导系数和热 收缩系数小等特点, 可在多个领域发挥重大作用。 现已被广泛用作一种多功能的无机材料, 广泛用于 保温涂料、胶粘剂、工程塑料、改性橡胶、电器绝 缘件中、玻璃钢、SMC、人造石、反光材料、石油 裂化催化剂等产品的优质填料。

\section{5 粉煤灰在环保方面的应用}

(1) 环保材料开发。粉煤灰因其独特的理化性能 而被广泛用于环保产业, 如用于垃圾卫生填埋填料, 用于制造人造沸石和分子篮, 利用粉煤灰制絮凝剂, 另外还可用作吸附剂等。

(2) 用于废水处理。粉煤灰在废水处理中主要

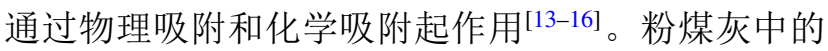
无机物质三氧化二铁、三氧化二铝、二氧化硅和氧 化钙等有多孔性和较大的比表面积, 因此, 有良好 的吸附作用和沉降作用。还可以利用粉煤灰在得出 最佳粉煤灰投加量、最佳PH和最佳温度下制备聚 合三氧化铁、硫酸铝等絮凝剂来处理污水, 改性后 的粉煤灰可应用于造纸、印染等行业产生的金属的 废水, 对 $\mathrm{Cr}^{6+}$ 的去除率达 $98.6 \%, \mathrm{Cd}^{2+}$ 的去除率高 达 $99.3 \%, \mathrm{~Pb}^{2+}$ 和 $\mathrm{Cu}^{2+}$ 等离子的去除率均在 $97 \%$ 以 上, 应用前景十分广阔。

\section{4 粉煤灰利用现状与展望}

随着国家对资源综合利用化的重视, 近几年出 台了大量固体废物综合利用的相关政策文件, 其中 也涉及到对粉煤灰综合利用的要求与鼓励, 如 《工 业固体废物资源综合利用评价管理暂行办法》、《建 材工业发展规划(2016-2020)年)》等[17]。即使在国家 大力支持下，我国的粉煤灰有效利用率仅有 $60 \%$, 与资源节约型国家, 如日本荷兰等废煤灰利用率 达 $100 \%$ 的国家, 我国任重道远。且随着我国经济高 速发展, 对资源要求日益增加, 因此对粉煤灰的综 合化利用无疑是前景所向。除此之外, 粉煤灰的综 合利用不仅能解决资源浪费问题, 还能促进生态环
境友好化、发展循环经济、创造就业机会。

\section{参考文献}

[1] 侯芹芹, 张创, 赵亚娟, 等.粉煤灰综合利用研究 进展. 应用化工, 2018, 47(6): 1281-1284.

[2] 杜艳霞. 粉煤灰资源化综合利用途径. 化工管理, 2019, 7: 56-57.

[3] 杨星, 呼文奎, 贾飞云, 等. 粉煤灰的综合利用技 术研究进展. 能源与环境, 2018, 4: 55-58.

[4] 白雪. 粉煤灰高附加值综合利用受政策支持. 中 国经济导报, 2013.

[5] 薛福连. 利用粉煤灰生产硅酸盐水泥熟料. 粉煤 灰,2007, 4: 41-43.

https://doi.org/10.3969/j.issn.1007-046X.2007.04. 014

[6] 李荣佳. 粉煤灰水泥浆的制备与应用研究. 陕西 煤炭, 2011, 4: 63-64.

https://doi.org/10.3969/j.issn.1671-749X.2011.04. 023

[7] 敬相海, 肖保杯, 姜涵. 大掺量粉煤灰水泥配制 研究. 粉煤灰, 2002, 14(1): 10-12.

https://doi.org/10.3969/j.issn.1007-046X.2002.01. 003

[8] 王亮. 粉煤灰综合利用研究. 天津大学, 2016. https://doi.org/10.7666/d.y1357780

[9] 易亚雄. 粉煤灰用作铁路填料的试验研究. 兰州 大学, 2008.

[10] 邓琨. 固体废弃物综合利用技术的现状分析-对 粉煤灰、煤䂥石、尾矿、脱硫石膏和秸秆综 合利用技术专业化的探析. 中国资源综合利用, 2011, 29(1): 33-42. https://doi.org/10.3969/j.issn.1008-9500.2011.01. 009

[11] 程改艳. 谈粉煤灰在公路工程中的应用. 山西建 筑, 2012, 38(2): 101-102. https://doi.org/10.3969/j.issn.1009-6825.2012.02. 060

[12] Jala S and Goyal D. Fly ash as a soil ameliorant for improving crop production - a review. Bioresource Technology, 2006, 97(9): 1136-1147.

[13] 沈王庆, 陈沁, 黄成华, 等. 内江市白马火电厂粉 煤灰的物理化学特性. 内江师范学院报, 2008, 23(2): 46-50. https://doi.org/10.3969/j.issn.1671-1785.2008.02. 012

[14] 陈稳. 利用粉煤灰处理生活污水. 河北理工大学, 唐山, 2005. 
[15] 程爱华, 王建东, 姚改焕. 粉煤灰在水处理中的 应用. 能源与环境, 2005, 7: 64-65.

https://doi.org/10.3969/j.issn.1008-9500.2005.07.

007

[16] 毛志红, 李卓卡索, 李晓雁, 等. 粉煤灰吸附苯胺

类有机废水的实验研究. 甘肃科技, 2011, 27(22):

49-50.

https://doi.org/10.3969/j.issn.1000-0952.2011.22.

018

[17] 宗边. 浅谈粉煤灰综合利用前景. 中国建材报, 2019年3月13日. 